\title{
How Video Rental Patterns Change as Consumers Move Online
}

\author{
Alejandro Zentner ${ }^{\dagger}$, Michael D. Smith ${ }^{\ddagger}$, Cuneyd Kaya ${ }^{\S}$ \\ azentner@utdallas.edu, mds@cmu.edu, cckaya@utdallas.edu
}

This Version: October 2012

Acknowledgements: The authors thank an anonymous video chain for generously providing data to support this research and Venkata Tumuluri, Samita Dhanasobhon, and Ketaki Potkar for providing outstanding research assistance. Smith acknowledges generous support from Carnegie Mellon's iLab and Zentner acknowledges generous support from the Center for the Analysis of Property Rights and Innovation (CAPRI). The authors are listed in reverse alphabetical order.

University of Texas at Dallas

* Heinz College, Carnegie Mellon University

$\S \quad$ University of Texas at Dallas 


\title{
How Video Rental Patterns Change as Consumers Move Online
}

\begin{abstract}
How will consumption patterns change when consumers move from brick-and-mortar to Internet markets? If consumers purchase more niche products online than at brick-andmortar stores, does this have something to do with the channel or is this solely due to selection effects: the types of consumers who decide to use the Internet channel or the types of products that consumers select to purchase online?

We address these questions using customer-level rental panel data obtained from a national video chain as it was closing many of its local stores. This allows us to observe how behavior changes when consumers are forced to move from brick-and-mortar to online consumption.

Our results suggest that when consumers move from brick-and-mortar to online channels they are significantly more likely to rent "niche" titles relative to "blockbusters." This suggests that a significant amount of niche product consumption online is due to the nature of the channel, not just due to selection effects.
\end{abstract}

Keywords: long tail, DVD rentals, natural experiment, empirical estimation. 


\section{Introduction}

Some observers believe that the emergence of the information economy, by transforming production and distribution costs as well as affecting consumers' preferences, has the potential to greatly change the answers to fundamental economic questions such as the decisions of how and what to produce. Although the new economy's impacts on performance, productivity, and organizations have been examined in some detail for various markets (e.g., Brynjolfsson and Hitt 1996; Acemoglu et al. 2007; Aral, Brynjolfsson, and Van Alstyne 2011; Miller and Tucker 2011), its impact on what goods are produced or sold has received more limited academic attention.

In this paper we focus on how one aspect of the new economy-online commercemight affect what goods are produced and sold. A variety of papers and articles have documented large differences between the types of products purchased online and offline (e.g., Brynjolfsson, Hu, and Smith 2003; Anderson 2006; Brynjolfsson, $\mathrm{Hu}$, and Simester 2011). However, these differences in purchase patterns across channels could be solely due to selection effects: heterogeneous consumers may sort into channels based on their tastes or consumers may choose the channel based on the types of products they want to purchase. Our objective in this paper is investigating whether observed differences in consumptions patterns between online and offline markets are solely due to selection, or whether the nature of the channel has some impact on consumer's choices.

Answering this question requires the use of customer-level panel data on online and offline purchases and an exogenous shock affecting consumers channel choices. In this paper we use just such a dataset for DVD rentals. We base our empirical analysis on household-level panel data from a large video rental chain that closed many physical locations during our study period. The market for DVD rentals has traditionally exhibited "superstar" effects, where a few top-selling products take the lion's share of all revenues (Rosen 1981); our focus is to empirically examine how the introduction of online commerce has changed the share of transactions taken by superstar versus niche DVDs.

In terms of descriptive statistics, we note that the top 100 most popular DVDs make up $85 \%$ of in-store rentals for our focal company but account for only $35 \%$ of the company's 
online rentals. However, we cannot use these simple statistics to conclude that online markets change consumer behavior because these statistics may be solely due to selection effects. Our approach to study whether online markets change consumer behavior is to examine how household-level rental patterns for popular and niche titles change when the exit of physical stores forces consumers to move from offline to online channels. Specifically, we use the exit of physical stores as an instrumental variable for the online versus offline channel choice. This instrument exploits transportation cost changes experienced by individuals located near the exiting stores (Forman, Ghose, and Goldfarb 2009; Brynjolfsson, Hu, and Rahman 2009). Our findings, in short, indicate that superstar DVD titles take a smaller share of the market as consumers shift from offline to online marketplaces.

From the standpoint of theory, online markets may (or may not) transform markets that have traditionally exhibited "superstar" effects. Long tail or superstar markets could derive from either supply-side or demand-side e-commerce effects (Brynjolfsson, $\mathrm{Hu}$, and Smith 2006; Brynjolfsson, Hu, and Smith 2010). On the supply side, for example, the selection of products available from the Internet channel is much wider than the selection available at physical stores. Online marketplaces can offer a larger selection of products than traditional physical stores can because the online channel has lower storage and inventory costs and there are no shelf space limitations. As a consequence, the concentration of overall sales across products may tend to decrease as transactions shift from offline to online channels.

On the demand-side, however, online commerce can change consumers' product choices even when the sets of products offered online and offline are identical. In part, this might happen because the ways consumers search for products online and offline are fundamentally different. At physical stores, finding a popular product may be easier than finding a niche product, even when both are available. Popular products typically occupy more prominent shelf space in physical stores versus niche products that are relegated to less visible positions. In online marketplaces, search tools may be used to promote the discovery of niche titles tailored to individual customers' preferences. However, personalization and recommendation engines and other search tools could also increase 
the concentration of product sales. For example, top 10 seller lists may tend to reinforce the popularity of already popular products. Similarly, recommendation systems may increase the concentration of product sales because they base their recommendations on actual sales and there is limited data for products that have low historical sales (Fleder and Hosanagar 2009; Oestreicher-Singer and Sundararajan 2011).

The answer to how consumption patterns change when consumers move online is important for both the academic literature and for managerial practice. If the observed differences between online and offline markets are solely due to selection, without an effect on aggregate consumption, then there is no need for producers to change their behavior - and in our context in particular, motion picture studios should continue to focus on producing blockbuster titles (Elberse 2008). However, if using online markets changes consumer behavior, then producers may wish to reexamine their current strategies and shift their production toward more "long tail" products.

\section{Literature}

Our results contribute most directly to a small empirical literature studying the effect of information technology on sales concentration patterns. While the "Long Tail" was considered one of the best ideas of 2005 by industry observers (Businessweek 2005), it is important to note that there is no general agreement in the academic literature regarding how online commerce will affect the concentration in product sales.

In this literature, Elberse and Oberholzer-Gee (2007) use aggregate data to study how online commerce affected the distribution of sales in the United States' home video industry from 2000 to 2005 . They use weekly data on video sales aggregated by title, and examine how the distribution of overall video sales changed over time. They find that, although the number of product choices increases, by the end of their study period superstar products comprised a larger proportion of sales than ever before. ${ }^{1}$ However, in contrast to Elberse and Oberholzer-Gee (2007) we find that for the DVD rental market

\footnotetext{
${ }^{1}$ Partly motivated by this result, Bar-Isaac, Caruana, and Cuñat (forthcoming) formulated a model in which a reduction in search costs generates both superstar and long tail effects.
} 
superstar products take a smaller share of the market as consumers shift from offline to online marketplaces. Our contrasting results may arise from differences between the DVD rental and retail markets (e.g., TV series represent an important share of total DVD sales, but not of DVD rentals); our different results may also arise from our ability to use household-level panel data versus their data which are aggregated at the title level.

Brynjolfsson, $\mathrm{Hu}$, and Simester (2011) examine the concentration of product sales for a retailer of women's clothing selling through both Internet and catalog channels. Using cross sectional data on sales, aggregated by item and channel, they find that the concentration of product sales is lower for the Internet channel than for the catalog channel. Importantly, they conclude that the differences in the product sales distributions are due to lower search costs on the Internet versus catalog channels, since the Internet and catalog channels' product selections for this retailer are identical. While Brynjolfsson, $\mathrm{Hu}$, and Simester (2011) examine Internet and catalog channels, our examination focuses on Internet and brick-and-mortar channels. In this regard, we note that the long tail hypothesis has been most frequently associated with storage and inventory costs being higher for brick-and-mortar stores than for more centralized warehouses, such as the inventory costs for Internet or catalog channels.

Specifically, our dataset includes household-level DVD rentals from both online and offline stores from the same company, allowing us to account for unobserved household heterogeneity. In this regard our paper is related to the research examining grocery shopping using household-level data for households that shop interchangeably at online and offline stores from the same grocery chain (e.g., Chu, Chintagunta, and Cebollada 2008). In this literature, our paper is most closely related to Pozzi's (2012) examination of brand exploration in grocery shopping online versus offline. Pozzi's (2012) findings indicate that brand exploration is more prevalent in physical stores than online. As consumption goods, however, groceries are substantially different than DVD rentals because groceries are typically consumed more repeatedly. ${ }^{2}$

\footnotetext{
${ }^{2}$ Our results also contribute to a growing literature on the impact of popularity and recommendation information on online sales of niche and popular titles. In this literature Tucker and Zhang (2011) study the impact of popularity information on sales, arguing that titles with niche appeal may benefit from being listed in popular product lists more than general appeal products do. Likewise, Fleder and Hosanagar
} 
Our examination of superstar and long tail effects uses individual-level panel data including information on consumers' transactions from both online and brick-and-mortar channels. We use these data to analyze how individuals change their consumption patterns when they are induced by store closures to move from in-store to online consumption.

\section{Data and Setting}

Our data come from a large video rental company that operates both brick-and-mortar stores and online DVD rental channels. For a monthly flat rate subscription, the customers in our data can rent DVDs online and receive them in the mail, and then exchange these DVDs either through the mail or at a physical store.

The selection of DVD titles available for rental at physical stores is a subset of the selection of titles available for rental online. While a typical store has a rotating selection of approximately 2,000 titles, the online channel has over 100,000 titles. The Internet channel has a much larger DVD selection than the selection available at physical stores because the online channel has lower storage and inventory costs. Storage costs are even lower for video streaming services; however, video streaming was in its infant stages of development during our study period, and our focal company did not offer a video streaming service during our period of analysis. Due to these storage capacity limitations, our focal company's physical stores stock more copies of new releases than of older titles. Inventory costs are also lower online than in physical stores because the company we study ships DVDs to its customers from a small number of centralized warehouses, compared with a substantially larger set of physical stores. Thus, as these shipping locations reach a much larger number of consumers than a physical store would, the law

(2009) and Oestreicher-Singer and Sundararajan (2011) analyze how peer-based automated recommendation lists influence online preferences for long tail and blockbuster products, with the former authors finding that recommendation lists can either increase or decrease sales of "long tail" products, and the latter authors finding that product categories that are more sensitive to recommendation networks are also more likely to have higher sales of long tail products. In contrast to our study, these studies focus on the online market exclusively and do not examine sales from physical stores or cross channel choices. Our paper is also related to Waldfogel (2012) who examines how Internet markets may affect the production of albums, documenting a growth in the number of new albums released annually since year 2000 and a decrease in the degree of music sales concentration in a few artists. 
of large numbers indicates that the company can reduce inventory costs by more accurately predicting demand from the online channel.

Our data cover DVD rental activity from both the online and in-store channels for all subscribing customers, and include more than 49 million rental transactions for the thirty week period from October 2, 2009 through April 29, 2010. Although consumers without a monthly subscription can rent DVDs from our company's physical stores, our data only include the information from consumers with a monthly subscription that allows the rental of an unlimited number of DVDs. ${ }^{3}$ Our customers maintain an online queue of DVD titles they wish to watch, and when they return a DVD, the company sends the next DVD title from that queue to the subscriber's home.

Our data include the renting subscriber, DVD title, transaction date, and whether the DVD was delivered by mail or exchanged at a physical store. In addition, we have the zip code for each subscriber, the address for each physical location operated by this firm, and the closing date for the locations that were closed during our study period. For approximately $56 \%$ of the subscribers we also have exact addresses, which, when combined with the address for each store in our sample, allows us to calculate the distance between each of these customers and their closest store. ${ }^{4}$

Table 1 presents the summary statistics for our data. The DVD rental market has experienced important changes during the last decade. Industry trends show that traditional physical stores have been displaced by online DVD rental services, and more recently by video streaming services and by physical kiosks. We do not know exactly how the number of subscribers changed during our period of analysis, because subscribers may not rent every week and we do not have a list of subscribers indicating when they signed up for service or canceled their subscriptions. But the decrease in the number of subscribers renting DVDs by the end of our study period shown in Table 1

\footnotetext{
${ }^{3}$ These subscription plans include a restriction on how many DVDs a subscriber can have out at any given time.

${ }^{4}$ We have exact addresses for all consumers who signed up for service after January 1, 2008. While this is not a random sample of the subscribers, using these addresses we are able to provide a finer-grained examination of how transportation costs influence channel selection than using the zip codes for all the subscribers.
} 
suggests that the number of subscribers decreased during this period. Our data come from a company that closed $15.2 \%$ of its physical stores during our period of analysis (see the last column of Table 1). Our focal company did not open new physical locations during the thirty-week study period, and thus the number of physical store locations is entirely driven by store exit. The substantial change in the number of physical rental stores will play a central role in our identification strategy since we will use store exit as an instrumental variable for online versus offline channel selection by consumers.

Rentals via mail represent $68.3 \%$ of all rentals, and DVD exchanges at physical stores represent the remaining 31.7\%. Averaging our information across subscriber-week observations with positive DVD rentals (subscribers may not rent every week and our data only record the rental instances), subscribers rented an average of 2.25 DVDs per week: 0.71 DVDs from the store and 1.54 DVDs by mail.

\begin{tabular}{|c|c|c|c|}
\hline \multicolumn{4}{|c|}{ Table 1: Summary Statistics } \\
\hline Week & Number of Transactions & Number of Subcribers with Positive Rentals & Number of Stores \\
\hline Week 1 & $1,547,158$ & 739,696 & 3,356 \\
\hline Week 2 & $1,511,517$ & 721,494 & 3,356 \\
\hline Week 3 & $1,520,978$ & 727,174 & 3,356 \\
\hline Week 4 & $1,580,138$ & 743,421 & 3,354 \\
\hline Week 5 & $1,526,952$ & 690,849 & 3,325 \\
\hline Week 6 & $2,212,001$ & 798,357 & 3,324 \\
\hline Week 7 & $1,764,180$ & 735,643 & 3,300 \\
\hline Week 8 & $1,590,305$ & 721,258 & 3,072 \\
\hline Week 9 & $1,736,078$ & 786,002 & 3,066 \\
\hline Week 10 & $1,607,267$ & 735,969 & 3,066 \\
\hline Week 11 & $1,660,696$ & 750,181 & 3,066 \\
\hline Week 12 & $1,725,464$ & 764,054 & 3,065 \\
\hline Week 13 & $1,661,685$ & 740,716 & 3,047 \\
\hline Week 14 & $1,744,056$ & 770,986 & 3,047 \\
\hline Week 15 & $1,765,719$ & 775,946 & 3,046 \\
\hline Week 16 & $1,693,175$ & 748,035 & 3,046 \\
\hline Week 17 & $1,732,115$ & 755,332 & 3,033 \\
\hline Week 18 & $1,733,123$ & 758,485 & 3,033 \\
\hline Week 19 & $1,629,584$ & 725,281 & 3,033 \\
\hline Week 20 & $1,620,146$ & 726,576 & 3,032 \\
\hline Week 21 & $1,633,609$ & 717,592 & 3,032 \\
\hline Week 22 & $1,637,397$ & 721,227 & 2,860 \\
\hline Week 23 & $1,648,239$ & 722,855 & 2,859 \\
\hline Week 24 & $1,625,214$ & 713,490 & 2,858 \\
\hline Week 25 & $1,656,037$ & 715,472 & 2,858 \\
\hline Week 26 & $1,617,684$ & 702,461 & 2,844 \\
\hline Week 27 & $1,478,658$ & 662,682 & 2,844 \\
\hline Week 28 & $1,441,504$ & 650,747 & 2,844 \\
\hline Week 29 & $1,442,232$ & 648,772 & 2,843 \\
\hline Week 30 & $1,432,050$ & 645,485 & 2,843 \\
\hline
\end{tabular}


Importantly, a monthly subscription fee allows the rental of a certain number of DVDs at a time, but subscribers do not pay a price each time they rent a DVD from either the online or offline channel. Thus, for subscribers, the DVD rental price is neither a driver of the online versus offline channel selection, nor of the specific DVD title choice.

\subsection{Popular and Niche Product Definitions}

A stream of prior research, while focusing on examining the potential of information technologies to transform the distribution of sales across products and channels, has classified products as either niche or popular. Products are typically classified as niche when they are less likely to be stocked in physical stores, or are only available after incurring a high search cost. In spite of this definition, because of data restrictions, prior studies classified products as niche or popular based primarily on product sales from the online channel and not on product sales from the offline channel. Our data have the advantage that they allow us to define the popularity of DVD titles during a week using information from both online and offline rental channels.

Classifying goods as either niche or popular based on online sales might be problematic if the distribution of sales across products online and offline are different. We know that firms choose which products to stock online and offline, and furthermore know that product availability by channel may influence consumers' channel choices. As an example of the possible problems that can occur when classifying products based solely on online sales, suppose that consumers buy a product online only when this product is not available at the physical store. If this situation is common for a given product then this product could be classified as popular using online sales, even though many consumers are buying it online precisely because it is not available in physical stores and therefore could be considered a niche product. Additionally, some online retailers, because they face low competition from physical stores, may specialize in selling only niche products that are less likely to be available at physical stores. For these retailers classifying top-selling products as popular and the remaining products as niche may be incorrect. 
Using our data, we can only provide comparisons of transactions online and offline for a single product category (DVD rentals) and within a single firm. However, within this major firm, we can compare the extent to which the selection of DVDs rented online is different than the selection of DVDs rented offline. We do this by using online and offline data aggregated at the national level, and computing the total number of rentals for each DVD title and each channel during each week. We then rank DVDs by popularity, computing two separate weekly ranks of DVDs using either online or offline rental information.

Our definition also allows for the popularity of a DVD to vary from week to week: a DVD that is popular at the beginning of the study period can become niche by the end the study period, since DVDs have short-lived popularity cycles. For example, $91(228,347)$ different DVD titles are among the top 10 (top 50, top 100) DVD titles for at least one week during our thirty-week study period.

Figure 1 shows that the rankings of DVD rentals computed using online rentals are somewhat different than the rankings of DVD rentals computed using offline rentals. For example, comparing the top 10 DVD titles based on either online and offline rental information shows that a weekly average of 7.3 DVD titles are included in both rankings, but 2.7 DVD titles are included in only one ranking. Similarly, for the top 50 and top 100 DVDs approximately $70 \%$ of the titles are included in both rankings and the remaining $30 \%$ of the DVD titles are included in only one ranking.

\section{Figure 1: Commonality Between Online and Offline Popular Titles}

\begin{tabular}{|c|c|c|c|c|c|c|c|}
\hline & Top 10 & & & Top 50 & & & \\
\hline Online & & Offline & Online & & Offline & Online & Offline \\
\hline $27 \%$ & $73 \%$ & $27 \%$ & $30 \%$ & $70 \%$ & $30 \%$ & $30 \%$ & $30 \%$ \\
\hline
\end{tabular}

Differences between the online and offline rankings of DVD titles may be due to selection effects and may also be due to other cross-channel differences on the demand 
side or on the supply side. For example, these differences could be driven by preference heterogeneity between consumers who disproportionately choose the online versus the offline channel, different display and promotional activities across channels, or differences in the selection and inventory of titles available from the offline and online channels. Using our data it is difficult to disentangle the degree to which each factor may contribute to the differences between online and offline rankings. This is partly because we do not observe inventory or title assortments online and offline, and moreover title assortments may vary across our company's physical stores. ${ }^{5}$

In this section we have noted that the specific titles that are popular in the online channel are somewhat different than the titles that are popular in the offline channel. Using our data we can generate popularity lists based on both online and offline rentals, and we will examine whether popular titles defined in this way will change as consumers move online.

\subsection{Superstars: Online versus Offline DVD Rental Distributions}

In Table 2 we see that superstar DVD titles take a substantially larger share of total rentals offline than they do online. For example, the top 100 DVD titles in our sample represent $84.6 \%$ of in-store rentals, but only $35.1 \%$ of online rentals.

Table 2: Cumulative Share of Weekly Top Ranked DVD Rentals by Channel

\begin{tabular}{|c|c|c|}
\hline & Rented Online and Delivered by Mail & Rented from the Physical Store \\
\hline Top 10 & $11.0 \%$ & $47.7 \%$ \\
\hline Top 50 & $26.4 \%$ & $77.6 \%$ \\
\hline Top 100 & $35.1 \%$ & $84.6 \%$ \\
\hline
\end{tabular}

Although the statistics in Table 2 may be suggestive of what might happen when consumers move from offline to online markets, we must be cautious when interpreting Table 2. From these statistics alone we cannot conclude that online commerce decreases

\footnotetext{
${ }^{5}$ Having acknowledged the limitations of our data for distinguishing between alternative explanations for the differences in the titles included in the rankings online versus offline, Table EA1 in the extended online appendix may provide some relevant information regarding the selection of titles available from each channel.
} 
the superstar nature of the DVD rental market since these differences in rental patterns across channels could be solely due to selection effects. For example, different rental concentrations may be due to heterogeneous tastes of the consumers who rent primarily online versus consumers who rent primarily offline. These differences may also be explained by selection effects due to consumers' impatience. If consumers are impatient regarding watching a newly-released DVD and do not wish to wait for the DVD to arrive in the mail, then consumers who typically rent from both channels may select to rent from the physical store more often than from the online store when they wish to watch popular versus non-popular DVDs.

Our objective is to examine whether consumption patterns change as consumers move online, or whether differences in online and offline consumption are solely due to selection effects. Although in this paper we do not seek to identify why consumers change consumption patterns when they move online, beyond selection effects, the differences in the statistics in Table 2 may be an effect of the channel. We argued in the introduction that the literature has identified long tail effects arising from demand and supply effects: differences in the way consumers search online and offline and a wider selection of products available at the Internet channel than at physical stores. Some demand and supply factors that are more specific to our context can also explain the statistics in Table 2. For example, the focal company's different display and promotional activities across channels may partly explain these statistics. Popular products occupy a disproportionate amount of prominent shelf space in the company's physical stores, but the focal company does not display or promote popular products as heavily in the online channel. In addition, the queue system for video rentals may also partly explain the statistics in Table 2. Consumers who do not frequently update their online queue of DVDs may end up watching older and less popular titles when they move to the online channel. Moreover, if stock-outs of popular titles are more frequent online than offline then consumers may also rent less popular titles when they move to the online channel. ${ }^{6}$

\footnotetext{
${ }^{6}$ However, as noted above it may be expected that stock-outs are more frequent at brick-and-mortar stores than online because online rentals are shipped from centralized warehouses. We monitored stock-outs at three physical stores and also monitored online stock-outs by opening two online accounts with the focal company. Our brief examination showed that stock-outs of popular titles are somewhat frequent both online and offline, and it is unclear whether stock-outs are more prevalent online or offline.
} 
We now present our empirical approach for examining whether consumers change rental patterns as they move online, or whether the differences in online versus offline consumption are primarily due to selection effects.

\section{Econometric Model}

As noted above, our objective is to study whether changes in which rental channel consumers use affects their selection of DVD rental titles, and establishing whether online markets affect the consumption of superstar versus long tail DVD titles. We showed in Table 2 that the distributions of DVD rentals online and offline are quite different. Superstar DVD titles in particular take a substantially larger share of all rentals made in physical stores than they do online. However, although these distributions are certainly suggestive about what would be expected when consumers move from offline to online markets, these differences do not necessarily imply that the rental channel changes a household's selection of DVD rental titles. Specifically, the different rental distributions online and offline in Table 2 could be explained solely by selection effects. Cross-section regressions would suffer from a similar problem, because these regressions obtain empirical identification from comparing DVD rental selections across heterogeneous consumers.

Our empirical approach then is to control for unobserved heterogeneity using panel data, exploiting changes in DVD rental activity across time and across rental channel for each household. For each household $i$ in each week $t$ we define the following variables: Share Popular $i$ is the share of the number of superstar DVD title rentals (weekly top 10, top 50, and top 100) divided by the total number of rentals, and Share Offline $i t$ is the share of the number of rentals made offline, divided by the total number of rentals made both online and offline.

We then use these variables to estimate the following fixed effect model:

\section{(1) Share Popular ${ }_{i t}=\alpha+\beta$ Share Offline Pit $+\gamma$ Total Rentals $_{i t}+\phi_{i}+\psi_{t}+\varphi_{z} x t+u_{i t}$}


The variable Total Rentals Rit $_{\text {in }}$ Model (1) represents the total number of DVD rentals made by household $i$ in week $t$. The coefficient $\beta$ in Model (1) measures how weekly changes in the share of DVDs rented from the physical store relate to weekly changes in the share of popular DVD rentals. We control for the weekly total DVD rentals from both online and offline channels because our objective is to examine the effect of channel choice conditional on the total amount of rental consumption (the online appendix presents results not controlling for weekly total DVD rentals). The model includes fixed effects for each household $\phi_{i}$ and for each week $\psi_{t}$, and includes zip code-specific trends $\varphi_{z} \times t$.

By using a longitudinal model we can "difference out" the time invariant unobserved characteristics of each household; for example household fixed effects capture income levels or household sizes that are unlikely to change substantially during a seven month period. The week fixed effects capture aggregate changes over time, such as changes in DVD rental consumption that can be caused by school breaks or seasons. To account for pre-existing trends at the level of the zip code, Model (1) also includes zip codeidiosyncratic trends. For example, these idiosyncratic trends may account for marketlevel changes, such as changes in Internet or cable television usage that might have affected rental consumption patterns during our study period. Identification in Model (1) arises from deviations from zip code-level trends in changes in the DVD rental selection and rental channel within households from week to week.

While our panel data approach allows us to control for the time invariant tastes of each household, and therefore accounts for the sorting of heterogeneous consumers into channels, Ordinary Least Squares estimates of Model (1) may still provide a misleading measurement of how the rental channel affects the selection of DVD rentals when a household's desire for popular versus non-popular DVDs changes over time. For example, consumers may choose to rent a popular DVD title from the physical store in weeks when they feel impatient about watching a popular newly released title and do not wish to wait for the DVD to arrive in the mail. The rental channel is a choice; and individuals' changes in their desires to watch popular versus non-popular DVDs may influence their channel selection, creating an endogeneity problem. In order to identify 
how changes in the rental channel affect the overall selection of DVD rental titles we would need to observe changes in individuals' shares of offline rentals that are not caused by weekly changes in the desire to watch popular versus non-popular DVDs.

To break this endogeneity problem, we use the exit of physical stores as an instrumental variable. The rationale for using the exit of physical stores as an instrument is that the exit of a store, by changing the transportation cost of traveling to the store for the individuals that previously rented DVDs from the closing store, increases the relative cost of renting DVDs from the physical channel. In turn, the increase in the relative cost of renting DVDs from the physical channel may induce consumers to shift their rentals from the offline to the online channel. Our instrument is valid as long as it affects the channel selection and can be excluded from Model (1). Specifically, the exit of a physical store is a valid instrument even when store closures are not random and are possibly related to a decrease in the local aggregate demand for DVD rentals, as long as store closures are unrelated to relative rental demands for popular versus non-popular DVD titles.

We will use two alternative models to test whether households change the share of transactions made from physical stores when the stores in their geographical market exit. First, we follow Brynjolfsson, Hu, and Rahman (2009) and assume that the transportation cost of traveling to the physical store increases when the number of physical stores in the zip code decreases. Brynjolfsson, Hu, and Rahman (2009), however, treat zip codes as isolated markets. By computing distances in miles among the zip codes' centroids using data from the United States Census we can extend Brynjolfsson, Hu, and Rahman (2009) in order to account for changes in the number of physical stores located in adjacent zip codes.

Specifically, we estimate the following first stage model:

(2) Share Offline $e_{i t}=\delta+\sum_{j=1}^{6} \theta_{j}$ Number of Stores in Zip Code $e_{i j t}+\rho$ Total Rentals $s_{i t}+$

$$
\vartheta_{i}+\tau_{t}+\zeta_{z} \times t+e_{i t}
$$


where $j$ equal to 1 represents the zip code where household $i$ resides, $j$ equal to $2(3,4,5$, and 6) represents zip codes with centroids located between zero and five (five and ten, ten and fifteen, fifteen and twenty, and twenty and thirty) miles away from the centroid of the zip code where household $i$ resides. We also note that the number of stores in a zip code changes over time through store exit.

We obtained the latitude and longitude for all physical stores and for the fraction of all consumers where we have the consumer's address. For these consumers we can compute the distance to the closest store in each week, and estimate the following model:

\section{(3) Share Offline ${ }_{i t}=\omega+\epsilon$ Distance to the Closest Store $_{i t}+\mu$ Total Rentals $_{i t}+\pi_{i}+\sigma_{t}+$}

$$
\eta_{z} x t+v_{i t}
$$

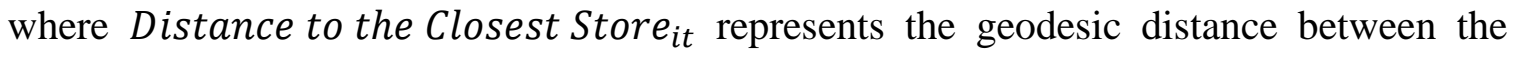
location of household $i$ and the closest physical store in week $t$. Note that the distances to the closest store change over time for households living near closing stores.

The focal company may naturally close its least successful stores, and the selection of which stores to close may be related to local demographic characteristics or to changes in the local market environment. However, we believe that the exit of stores is unlikely to be affected by individuals' high frequency changes in their relative desires to rent popular versus non-popular DVDs, in which case our instrument is orthogonal to the error. Moreover, the zip code-specific trends in our regression control for pre-existing trends at the level of the zip code that might have induced stores closures. These trends may include trends induced by demographics, Internet or cable connectedness, or the local market environment. In sum, our instrument is valid if the high-frequency timing of store closure is unrelated to the relative desire to rent popular versus non-popular titles. We also show in online appendix EA2 that store closures are unrelated to the number of highspeed Internet providers in each zip code. ${ }^{7}$

\footnotetext{
${ }^{7}$ The exit of physical stores may have potentially increased stock-outs of popular titles from surviving physical stores, leading to an increase in niche title consumption from physical stores. However, aggregate rentals of niche titles from physical stores do not show an upward time trend during the period of analysis.
} 
It is important to note that our company faces competition from other DVD rental companies, and during our study period other companies rented DVDs exclusively "by mail," from kiosks, and from physical stores. ${ }^{8}$ The entry of DVD rental kiosks (and even the mere existence of rental kiosks prior to our study period) and competition from other physical DVD rental stores might be thought to represent a challenge to our identification strategy because households living near closing stores may rent popular DVD titles from other companies while they continue to rent niche DVD titles from our focal company. If this happens we would observe a change in the relative demand for popular versus niche titles associated with the exit of stores, when the unobserved consumption bundle of niche and superstar titles from both the focal company and the competitors might remain unchanged. This would invalidate the use of our instrument.

However, as noted above, our data only include information from consumers with a "Rent by Mail" subscription, and these subscribers do not pay a separate price each time they rent a DVD from either the online or offline channel. Although in theory the consumers in our data may simultaneously have subscriptions with our focal company and may pay extra to have subscription with other competing companies or to rent DVDs from competitive outlets, we are doubtful that this is a common practice. In this regard, we note that the market leader in rentals via kiosks, Redbox, considers that, "people who use the kiosks tend to be casual viewers who don't want to be tied down to subscriptions or membership fees" (Green 2009). More importantly, in the Appendix, we use historical data on Redbox locations to show that our conclusions in the main text are robust to restricting the analysis to locations without a local Redbox kiosk.

Of course, it is also true that households living near closing stores may decide to cancel their subscriptions from the focal company, and begin renting from other companies (e.g., from Netflix) in which case their rentals will not be recorded in our data. For this reason, in the results below, we analyze the sensitivity of our results to attrition using a balanced panel of consumers.

\footnotetext{
${ }^{8}$ The market could also be defined more broadly as consumers may consider DVD rentals as a substitute for cable television, DVD purchases, movie theaters, or other entertainment options such as playing games or using the Internet.
} 


\section{Summary Statistics and Results}

\subsection{Summary Statistics}

Table 3 presents summary statistics for our data, computed using household-week observations. Consumers in our data rent on average 2.25 DVDs per week and they rent $28.4 \%$ of these DVDs from physical stores. On average, top 10 (top 50, top 100) DVD titles represent $20.6 \%(39.6 \%, 47.9 \%)$ of all transactions. The average number of stores per zip code is 0.52 . We will use these statistics below in interpreting our regression results.

\section{Table 3: Additional Summary Statistics}

\begin{tabular}{|c|c|c|c|c|}
\hline & Mean & Standard Deviation & $5 \%$ & $95 \%$ \\
\hline Total DVD Rentals per Week & 2.255 & 1.391 & 1 & 5 \\
\hline Share of Offline Rentals & 0.284 & 0.373 & 0 & 1 \\
\hline Share of Rentals Taken by Top 10 Titles & 0.206 & 0.324 & 0 & 1 \\
\hline Share of Rentals Taken by Top 50 Titles & 0.396 & 0.406 & 0 & 1 \\
\hline Share of Rentals Taken by Top 100 Titles & 0.479 & 0.419 & 0 & 1 \\
\hline Stores per Zip Code† & 0.525 & 0.612 & 0 & 2 \\
\hline These statitics are computed using 20,249,021 observations. & & \\
\hline We explain below that some regressions do not use all the observations. & & \\
\hline †In the data, zip codes have between zero and three stores. & & \\
\hline
\end{tabular}

\subsection{Ordinary Least Square Results}

Table 4 presents the OLS estimation results for Model (1). The standard errors are clustered at the household level to allow for the possibility of serial correlation over time. The regressions include fixed effects for each week, over a million and a half fixed effects at the household level, and approximately twenty five thousand zip code-specific trends. The results show that households increase the fraction of rentals of popular DVDs when they rent more DVDs from the physical store. The coefficient estimates on the fraction of offline rentals are both statistically and economically significant.

The sizes of the coefficient estimates on the fraction of offline rentals indicate that a household that decreases the fraction of DVDs rented from the physical store from 
twenty eight percent to zero, as might be the case when physical stores are eliminated as a choice for consumers (note that the mean of the share of offline rentals in Table 4 is 0.28), would decrease the fraction of top 10 (top 50, top 100) DVD rentals by 10.2 (13.9, 13.1) percentage points. These effects are substantial. For example, Table 3 above shows that the top 10 DVD titles represent twenty percent of all rental transactions. Given this, the coefficient estimate on the share of offline rentals in Column I of Table 4 indicates that top 10 DVD titles would take approximately ten percent of all transactions if all physical stores go out of business, which represents a fifty percent decrease in the share of transactions taken by the top 10 DVD titles. Columns II and III of Table 4 indicate that when consumers move all their transactions to the online channel the share of transactions taken by the top 50 and top 100 titles would decrease by thirty five and twenty seven percent respectively. ${ }^{9}$

\begin{tabular}{|l|c|c|c|}
\hline \multicolumn{4}{|c|}{ Table 4: Share of Popular Rentals - OLS Estimates } \\
\hline & I & II & III \\
\hline Share of Offline Rentals & $0.3650^{* * *}$ & $0.4967 * * *$ & $0.4682^{* * *}$ \\
\hline (mean 0.28) & $(0.0003)$ & $(0.0004)$ & $(0.0004)$ \\
\hline Total DVD Rentals & $-0.0120 * * *$ & $-0.0090^{* * *}$ & $-0.0066^{* * *}$ \\
\hline (mean 2.25) & $(0.0001)$ & $(0.0001)$ & $(0.0001)$ \\
\hline Constant & $-0.0142 * * *$ & $-0.0202^{* * *}$ & $-0.0118^{* * *}$ \\
\hline & $(0.0004)$ & $(0.0004)$ & $(0.0005)$ \\
\hline Observations & $20,249,021$ & $20,249,021$ & $20,249,021$ \\
\hline R-squared & 0.3251 & 0.4248 & 0.4268 \\
\hline Includes fixed effects for both weeks (30) and individuals $(1,529,028)$, and ZIP code-specific trends (24,648). \\
\hline Standard errors in parentheses are clustered by household. \\
\hline The mean of the dependent variable is 0.20 in Column I, 0.39 in Column II, and 0.47 in Column III. \\
\hline * significant at 10\%; ** significant at 5\%; ** significant at 1\% \\
\hline
\end{tabular}

The sign of the coefficient estimates on total DVD rentals per week is negative and economically small. The negative sign may be unsurprising because individuals may tend to rent top DVDs first, and rent DVDs that are further down the popularity distribution

\footnotetext{
${ }^{9}$ Although the coefficient is greater for the top 50 and top 100 titles than for the top 10 titles, the impact is smaller as a percentage change because the size of the dependent variable is also greater for the top 50 and top 100 titles compared to the top 10 titles.
} 
during weeks when they increase the number of DVD rentals. Renting an additional DVD in a week reduces the fraction of top 10, top 50, or top 100 DVD rentals by between 0.6 and 1.2 percentage points.

\subsection{Instrumental Variable Results}

The regressions in Table 5 present our first stage results examining how channel choice is affected by the exit of stores. The results in Column I of Table 5 show that when one store exits from a zip code, consumers living in that zip code decrease their share of offline rentals by an average of 2.2 percentage points (or approximately $7.8 \%$ of the transactions made at physical stores). This result is expected because, by increasing the transportation cost, the exit of a store from a zip code increases the relative cost of renting from the physical store for households that reside in that zip code.

Our first stage results are consistent with the prior literature showing that the likelihood of purchasing products online decreases as the number of stores in the zip code increases (Brynjolfsson, $\mathrm{Hu}$, and Rahman 2009). However, Brynjolfsson, $\mathrm{Hu}$, and Rahman (2009) treat zip codes as isolated geographic markets, while we can also provide information regarding the size of the geographic market. ${ }^{10}$

Column I of Table 5 shows how the impact of the exit of a store on channel choice dissipates for households living further away from the closing store. The results in Column I of Table 5 indicate that the closure of a store within the zip code where a household resides has an impact on the household's channel choice that is seven times larger than the impact of the closure of a store in other zip codes with centroids located less than five miles away from the centroid of the zip code where the household resides. The results in Column I of Table 5 also show how the exit of stores in zip codes located further away have no impact on households' channel choices.

\footnotetext{
${ }^{10}$ Other differences between our first stage regressions and the analysis in Brynjolfsson, Hu, and Rahman (2009) are that they do not observe transactions from physical stores; they use cross sectional data on online and catalog channels rather than panel data on online and brick and mortar channels.
} 


\begin{tabular}{|c|c|c|}
\hline & I & II \\
\hline Number of Stores in the Zip Code Where the & $0.02239 * * *$ & na \\
\hline Household Resides (mean 0.52) & $(0.00078)$ & na \\
\hline Number of Stores in Zip Codes between Zero & $0.00304 * * *$ & na \\
\hline and Five Miles Away (mean 2.17) & $(0.00031)$ & na \\
\hline Number of Stores in Zip Codes between Five & -0.00004 & na \\
\hline and Ten Miles Away (mean 5.23) & $(0.00019)$ & na \\
\hline Number of Stores in Zip Codes between Ten & 0.00004 & na \\
\hline and Fifteen Miles Away (mean 6.56) & $(0.00017)$ & na \\
\hline Number of Stores in Zip Codes between Fifteen & -0.00004 & na \\
\hline and Twenty Miles Away (mean 6.89) & $(0.00017)$ & na \\
\hline Number of Stores in Zip Codes between Twenty & -0.0001 & na \\
\hline and Thirty Miles Away (mean 12.80) & $(0.00011)$ & na \\
\hline Distance to the Closest Store in Miles & na & $-0.00898 * * *$ \\
\hline (mean 3.6) & na & $(0.00035)$ \\
\hline \multirow[t]{2}{*}{ Squared Distance to the Closest Store in Miles } & na & $0.00012 * * *$ \\
\hline & na & $(0.00001)$ \\
\hline Total DVD Rentals & $0.02605 * * *$ & $0.02518 * * *$ \\
\hline (mean 2.25 in Columns I and II) & $(0.00008)$ & $(0.00011)$ \\
\hline \multirow[t]{2}{*}{ Constant } & $-0.02364 * * *$ & $-0.02841 * * *$ \\
\hline & $(0.00042)$ & $(0.00062)$ \\
\hline Observations & $20,249,021$ & $9,141,694$ \\
\hline F-test (global test for the excluded instruments in the second stage) & 155.5 & 399.7 \\
\hline R-squared & 0.2935 & 0.3199 \\
\hline \multicolumn{3}{|c|}{ Includes fixed effects for both weeks (30) and individuals (Column I 1,529,028; Column II 855,996), and } \\
\hline \multicolumn{3}{|c|}{ ZIP code-specific trends (Column I 24,648; Column II 19,233). Standard errors in parentheses are clustered by household. } \\
\hline \multicolumn{3}{|l|}{ The mean of the dependent variable is 0.28 in Column I and 0.25 in Column II. } \\
\hline$*$ significant at $10 \% ; * *$ significant at $5 \% ; * * *$ significant at $1 \%$ & & \\
\hline
\end{tabular}

We also use the geodesic distance from consumers' locations to the closest physical stores as an alternative instrument. We acknowledge that some consumers may use stores that are not the closest to their home address (e.g., stores nearby their working location or in the way when running errands), but we still believe that using the closest store to the home address is useful as an approximation for the transportation costs of using the offline channel. Comparing unconditional means, households living less than one mile away from a physical store make $29.4 \%$ of their rentals offline and households living more than 20 miles away from physical stores make $10.3 \%$ of their rentals offline. Column II of Table 5 shows the estimates for Model (3) using the square of the distance to the closest store as an additional covariate to account for non-linear transportation 
costs. ${ }^{11}$ For example, the results in Column II of Table 5 indicate that households residing near a closing physical store will decrease average rentals from physical stores by 8.8 percentage points (or approximately $35.2 \%$ of the transactions made from physical stores) when the new closest store for these households is ten miles away. Moreover, the sizes of the coefficients indicate that households that reside near a closing physical store will decrease the transactions made from physical stores to approximately zero when the new closest store for these households is thirty miles away.

The results for the second stage of Model (1) in Table 6 still show that individuals increase the fraction of popular DVD rentals when they rent more DVDs from the physical store. The first three columns use Column I in Table 5 for the first stage regression and the last three columns use Column II in Table 5 for the first stage regression. In the first three regressions in Table 6 the sizes of the coefficient estimates on the fraction of offline rentals indicate that when a household decreases the fraction of DVDs rented from physical stores from twenty eight percent to zero, the fraction of top 10 (top 50, top 100) DVD rentals decreases by $10.7(10.0,7.3)$ percentage points. In the last three regressions in Table 6 the sizes of the coefficient estimates on the fraction of offline rentals indicate that when a household decreases the fraction of DVDs rented from the store from twenty five percent to zero (note that the mean of the share of offline rentals for the last three columns of Table 6 is 0.25 ), the fraction of top 10 (top 50, top 100) DVD rentals decreases by $10.4(9.9,8.9)$ percentage points.

Table 6: Share of Popular Rentals - IV Estimates - Second Stage

\begin{tabular}{|l|c|c|c|c|c|c|}
\hline & I & II & III & IV & V & VI \\
\hline & Top 10 & Top 50 & Top 100 & Top 10 & Top 50 & Top 100 \\
\hline Share of Offline Rentals & $0.3856^{* * *}$ & $0.3597^{* * *}$ & $0.2638^{* * *}$ & $0.4184^{* * *}$ & $0.3969^{* * *}$ & $0.3594^{* * *}$ \\
\hline (mean 0.28 in Columns I through III & $(0.0372)$ & $(0.0457)$ & $(0.0473)$ & $(0.0391)$ & $(0.0511)$ & $(0.0524)$ \\
\hline and 0.25 in Columns IV through VI) & & & & & & \\
\hline Total DVD Rentals & $-0.0125^{* * *}$ & $-0.0054^{* * *}$ & -0.0013 & $-0.0129 * * *$ & $-0.0068^{* * *}$ & $-0.0044^{* * *}$ \\
\hline (mean 2.25 in Columns I through VI) & $(0.0010)$ & $(0.0012)$ & $(0.0012)$ & $(0.0010)$ & $(0.0013)$ & $(0.0013)$ \\
\hline Constant & $-0.0137 * * *$ & $-0.0234 * * *$ & $-0.0166^{* * *}$ & $-0.0092^{* * *}$ & $-0.0177^{* * *}$ & $-0.0086^{* * *}$ \\
\hline Observations & $(0.0010)$ & $(0.0012)$ & $(0.0012)$ & $(0.0013)$ & $(0.0016)$ & $(0.0017)$ \\
\hline
\end{tabular}

Includes fixed effects for both weeks (30) and individuals (Columns I through III 1,529,028; Columns IV through VI 855,996), and

ZIP code-specific trends (Columns I through III 24,648; Columns IV through VI 19,233). Standard errors in parentheses are clustered by household.

The mean of the dependent variable is 0.20 in Column I, 0.39 in Column II, 0.47 in Column III, 0.19 in Column IV, 0.38 in Column V, and 0.46 in Column VI.

* significant at $10 \%$; * significant at $5 \%$;** significant at $1 \%$

\footnotetext{
${ }^{11}$ We note that excluding the square of the distance from the first stage (or alternatively including higher order polynomials) causes no substantial change in the second stage results.
} 
Comparing the Instrumental Variables results in Table 6 with the OLS results in Table 4, we observe that the size of the coefficient estimates on the fraction of offline rentals are similar for top 10 titles and smaller, but still significant both economically and statistically, for top 50 and top 100 titles.

As in Table 4, the coefficient estimates on total DVD rentals per week in Table 6 are negative and economically small.

\subsection{Sensitivity of Results to Attrition}

Table 1 suggests that our focal company lost subscribers during our study period. Additionally, the customer base exhibits a high churn rate likely fueled by free of charge trial period offers. Our panel of data is therefore unbalanced. An unbalanced panel does not generate biased estimates when the reason for having missing observations is not correlated with the regression error term. For example, subscribers that rent DVDs in only one week during our study period do not bias the estimates since time demeaning for such observations yields all zeros. But in order to examine whether or not our previous empirical results are driven by changes in the customer base, in this section we rerun our regressions using a balanced panel of subscribers.

Table 7 presents OLS results analogous to those in Table 4, but only including the information from subscribers who rented at least one DVD in both the initial and final four weeks of our study period. There are 764,875 such subscribers, or approximately half of the total number of subscribers compared with Table 4. In Table 7 the coefficient estimates on both the fraction of offline rentals and the total DVD rentals per week variables are very similar to those in Table 4.

The similarity of the results in Tables 4 and 7 indicates that the effects of the online versus offline channel choice on superstar DVD rentals are not significantly different for subscribers who maintained subscriptions during the entire length of our study period versus subscribers who did not. 
Table 7: Share of Popular Rentals - OLS Estimates - Balanced Panel

\begin{tabular}{|l|c|c|c|}
\hline & I & II & III \\
\hline Share of Offline Rentals & Top 10 & Top 50 & Top 100 \\
\hline (mean 0.30) & $0.3713 * * *$ & $0.5003 * * *$ & $0.4701 * * *$ \\
\hline Total DVD Rentals & $(0.0003)$ & $(0.0004)$ & $(0.0004)$ \\
\hline (mean 2.33) & $-0.0123 * * *$ & $-0.0093 * * *$ & $-0.0070 * * *$ \\
\hline Constant & $(0.0001)$ & $(0.0001)$ & $(0.0001)$ \\
\hline & $-0.0079 * * *$ & $-0.0161 * * *$ & $-0.0089 * * *$ \\
\hline Observations & $(0.0004)$ & $(0.0005)$ & $(0.0005)$ \\
\hline R-squared & $15,239,005$ & $15,239,005$ & $15,239,005$ \\
\hline
\end{tabular}

Includes fixed effects for both weeks (30) and individuals (764,875), and ZIP code-specific trends (21,396).

Standard errors in parentheses are clustered by household.

The mean of the dependent variable is 0.22 in Column I, 0.41 in Column II, and 0.49 in Column III.

* significant at $10 \% ; * *$ significant at $5 \%$; *** significant at $1 \%$

However, the value of a subscription may be greater as the distance to an offline store decreases, since having a physical store nearby provides the additional value of exchanging DVDs at the store. Since attrition in our data is likely correlated with the exit of physical stores, attrition might bias our instrumental variable results. Tables 8 and 9 present first and second stage regressions analogous to those in Tables 5 and 6 , but using the balanced sub-sample of our data.

The results for both the first stage and second stage regressions in Tables 7 and 8 using the balanced sub-sample are similar than those in Tables 5 and 6 using the entire sample. This similarity suggests that our previous results using the entire sample are not driven by changes in the profile of customers over time. 
Table 8: Share of Offline Rentals - First Stage - Balanced Panel

\begin{tabular}{|c|c|c|}
\hline & I & II \\
\hline Number of Stores in the Zip Code Where the & $0.02114 * * *$ & na \\
\hline Household Resides (mean 0.53) & $(0.00085)$ & na \\
\hline Number of Stores in Zip Codes between Zero & $0.00277 * * *$ & na \\
\hline and Five Miles Away (mean 2.17) & $(0.00034)$ & na \\
\hline Number of Stores in Zip Codes between Five & -0.00009 & na \\
\hline and Ten Miles Away (mean 5.23) & $(0.00020)$ & na \\
\hline Number of Stores in Zip Codes between Ten & 0.00013 & na \\
\hline and Fifteen Miles Away (mean 6.58) & $(0.00018)$ & na \\
\hline Number of Stores in Zip Codes between Fifteen & 0.00002 & na \\
\hline and Twenty Miles Away (mean 6.93) & $(0.00018)$ & na \\
\hline Number of Stores in Zip Codes between Twenty & -0.00011 & na \\
\hline and Thirty Miles Away (mean 12.88) & $(0.00012)$ & na \\
\hline Distance to the Closest Store in Miles & na & $-0.00863 * * *$ \\
\hline (mean 3.49) & na & $(0.00043)$ \\
\hline \multirow[t]{2}{*}{ Squared Distance to the Closest Store in Miles } & na & $0.00011 * * *$ \\
\hline & na & $(0.00001)$ \\
\hline Total DVD Rentals & $0.02518 * * *$ & $0.02406 * * *$ \\
\hline (mean 2.33 in Column I and 2.34 in Column II) & $(0.00009)$ & $(0.00014)$ \\
\hline \multirow[t]{2}{*}{ Contant } & $-0.00741 * * *$ & -0.00026 \\
\hline & $(0.00046)$ & $(0.00073)$ \\
\hline Observations & $15,239,005$ & $5,667,199$ \\
\hline F-test (global test for the excluded instruments in the second stage) & 114.5 & 256.7 \\
\hline R-squared & 0.2737 & 0.2888 \\
\hline \multicolumn{3}{|c|}{ Includes fixed effects for both weeks (30) and individuals (Column I 764,875; Column II 288,845), and } \\
\hline \multicolumn{3}{|c|}{ ZIP code-specific trends (Column I 21,396; Column II 15,770). Standard errors in parentheses are clustered by household. } \\
\hline \multicolumn{3}{|l|}{ The mean of the dependent variable is 0.30 in Column I and 0.28 in Column II. } \\
\hline$*$ significant at $10 \% ; * *$ significant at $5 \% ; * * *$ significant at $1 \%$ & & \\
\hline
\end{tabular}

Table 9: Share of Popular Rentals - IV Estimates - Second Stage - Balanced Panel

\begin{tabular}{|c|c|c|c|c|c|c|}
\hline & I & II & III & IV & $\mathbf{V}$ & VI \\
\hline & Top 10 & Top 50 & Top 100 & Top 10 & Top 50 & Top 100 \\
\hline Share of Offline Rentals & $0.4129 * * *$ & $0.3147 * * *$ & $0.2042 * * *$ & $0.4125 * * *$ & $0.3800 * * *$ & $0.3546 * * *$ \\
\hline (mean 0.30 in Columns I through III & $(0.0443)$ & $(0.0539)$ & $(0.0556)$ & $(0.0502)$ & $(0.0650)$ & $(0.0658)$ \\
\hline \multicolumn{7}{|l|}{ and 0.28 in Columns IV through VI) } \\
\hline Total DVD Rentals & $-0.0133 * * *$ & $-0.0047 * * *$ & -0.0003 & $-0.0129 * * *$ & $-0.0068 * * *$ & $-0.0047 * * *$ \\
\hline (mean 2.33 in Columns I through III & $(0.0011)$ & $(0.0014)$ & $(0.0014)$ & $(0.0012)$ & $(0.0016)$ & $(0.0016)$ \\
\hline \multicolumn{7}{|l|}{ and 2.34 in Columns IV through VI) } \\
\hline \multirow[t]{2}{*}{ Constant } & $-0.0076^{* * *}$ & $-0.0174 * * *$ & $-0.0108 * * *$ & $-0.0044 * * *$ & $-0.0128 * * *$ & $-0.0051 * * *$ \\
\hline & $(0.0005)$ & $(0.0007)$ & $(0.0007)$ & $(0.0007)$ & $(0.0008)$ & $(0.0009)$ \\
\hline Observations & $15,239,005$ & $15,239,005$ & $15,239,005$ & $5,667,199$ & $5,667,199$ & $5,667,199$ \\
\hline \multicolumn{7}{|c|}{ Includes fixed effects for both weeks (30) and individuals (Columns I through III 764,875; Columns IV through VI 288,845), and } \\
\hline \multicolumn{7}{|c|}{ ZIP code-specific trends (Columns I through III 21,396; Columns IV through VI 15,770). Standard errors in parentheses are clustered by household. } \\
\hline \multicolumn{7}{|c|}{ The mean of the dependent variable is 0.22 in Column I, 0.41 in Column II, 0.49 in Column III, 0.21 in Column IV, 0.40 in Column V, and 0.48 in Column VI. } \\
\hline * significant at $10 \%$; ** significant at $5 \%$; * & significant at $1 \%$ & & & & & \\
\hline
\end{tabular}


Regressions in the online appendix show various other sensitivity tests for our results including results that exclude total DVD rentals as a covariate in Tables 4, 5, and 6 (Appendix EA3, Tables EA3, EA4, and EA5), results that only use subscribers where we have the consumer's physical address in Table 4, Column I of Table 5 and Columns I through III of Table 6 (Appendix EA3, Tables EA6, EA7, and EA8), and results examining rentals of "top 2,000" titles (those that are likely to be stocked in both physical and online channels) (Appendix EA4). Our main results are robust to each of these considerations.

\section{Discussion}

As the proportion of commerce conducted online increases, will producers and retailers need to re-evaluate their investment and inventory choices? Answering this question is complicated by selection effects surrounding the types of consumers who purchase online and the types of products that consumers choose to purchase online. While early research has observed a large proportion of sales online in niche products, it is unclear whether this observation is merely a reflection of the characteristics of the consumers who select the channel, or of the types of products that consumers select to purchase online versus offline, or whether it might reflect a change in consumption patterns caused by the characteristics of the Internet channel.

Breaking this endogeneity requires an exogenous shift in the cost of purchasing online, and the ability to observe customer-level purchase decisions by channel before and after the shift. Our data provide us with just such an opportunity. Our data document customerlevel rental decisions before and after their local video rental store closes, and our empirical analysis suggests that when consumers move online they are much less likely to rent blockbuster titles than they were previously.

While our objective in this paper has been to examine how channel selection affects consumption patterns, our results showing how the impact of store exit on channel choice varies depending on where consumers live relative to the closing store, also complement and extend the prior literature on transportation costs and channel selection (e.g., 
Brynjolfsson, Hu, and Rahman 2009; Forman, Ghose, and Goldfarb 2009). Specifically, our data are substantially more granular than those used in previous work studying this question. ${ }^{12}$ Although our results extend the prior literature on channel selection and transportation costs, our examination of how changes in home-store distances affect channel selection in this paper is presented in the context of a first stage regression and is not the main research focus. Conducting a more detailed investigation of how transportation costs influence the online versus offline channel selection using our data is a potential avenue for further research.

Our main result, indicating that when consumers move to online channels they decrease their likelihood of renting popular titles, is of course not without limitations. Importantly, while we examine how consumption changes when consumers move online we do not examine why this change in consumption patterns occurs. Moreover, our results only provide evidence concerning a specific market, and are not necessarily generalizable to other environments. Online commerce could have heterogeneous impacts across industries, and transform different markets into either a "long tail" or "superstar" market based on the specific nature of each industry. For example, a mechanism that may partly underlie our results is that our focal company does not display or promote popular products as heavily in the online channel as it does in the brick-and-mortar channel. While this characteristic is typical across various online versus brick-and-mortar channels, it might be more pronounced for the specific market we study.

Also specific to our focal market is the queue system for online consumption, and this characteristic may provide two additional mechanisms leading to a decrease in the consumption of superstar DVDs as consumers move online. First, stock-outs may be expected to be more prevalent at brick-and-mortar stores than online because the centralized shipping locations used by Internet channels can more accurately predict

\footnotetext{
${ }^{12}$ We use a panel of consumers and know the zip code for all consumers, exactly where consumers live and how far they are from physical stores for a fraction of consumers. In contrast, Brynjolfsson, $\mathrm{Hu}$, and Rahman (2009) use cross-sectional data and Forman, Ghose, and Goldfarb (2009) are only able to use cities as the definition of where consumers live. We also observe household-level transactions from online and from physical channels as opposed to sales from online and catalog channels as used in Brynjolfsson, $\mathrm{Hu}$, and Rahman (2009), or as opposed to city-level sales ranks from the online channel only as used in Forman, Ghose, and Goldfarb (2009).
} 
demand than physical stores can. However, it is possible that stock-outs are more frequent online than at brick-and-mortar stores for our focal company in which case the consumption of popular titles would decrease as consumers move online. ${ }^{13}$ Second, it is also possible that consumers do not frequently update their online queues, leading consumers to rent older or less popular DVD titles. More generally, while we focus on examining how the shift from offline to online rentals affects the share of transactions taken by superstar versus long tail titles and whether differences in concentration are solely due to selection effects, we do not examine whether these changes are caused by demand versus supply side effects (selection of titles online versus offline, promotional and search differences online versus offline, queues, and stock-outs). Identifying how our observed effects are determined by supply versus demand side factors is an important avenue of future research.

In addition, even focusing on a single market, our results could vary over time; for example, early adopters of "Rent by Mail" subscriptions might be more interested in niche DVD titles than late adopters are. In this regard, we do believe that our analysis of a mature market provides a more useful examination of the market-level impact of online commerce on product concentration than an analysis of a nascent market would. Although our period of analysis is too short to examine how the results change over time, this examination is also a potential avenue for future research.

While the observation of a large proportion of sales online in niche products might merely be due to selection effects, our results show that there is a change in consumption patterns caused by the characteristics of the Internet channel. As a consequence, our finding that online channels may shift DVD consumption away from blockbuster titles and toward more niche titles may have implications for movie producers. Specifically, movie producers have typically faced a market where a small number of hits made up the lion's share of industry profits. Our results suggest that this historical pattern of highly concentrated transactions in a handful of titles might have been driven by the characteristics of the offline channel, and movie studios may wish to shift their resources toward more "long tail" titles as consumers move online. There is obviously a need for

\footnotetext{
${ }^{13}$ See footnote 6.
} 
more research to be in a position to predict the degree to which Internet markets change the incentives of movie producers and allow for the production of more niche titles; and we believe this paper is a first step in that direction. 


\section{References}

Acemoglu, Daron, Philippe Aghion, Claire Lelarge, John Van Reenen, Fabrizio Zilibotti. 2007. Technology, Information and the Decentralization of the Firm. Quarterly Journal of Economics 122 1759-1799.

Anderson, Chris. 2006. The Long Tail: Why The Future of Business Is Selling Less of More. New York, NY: Hyperion.

Aral, Sinan, Erik Brynjolfsson, Marshall Van Alstyne. 2011. Information, Technology, and Information Worker Productivity. Information Systems Research, Forthcoming.

Bar-Isaac, Heski and Caruana, Guillermo and Cuñat, Vicente. Forthcoming. Search, design, and market structure. American Economic Review. Forthcoming.

Brynjolfsson, Erik, Lorin Hitt. 1996. Paradox Lost? Firm-level Evidence on the Returns to Information Systems Spending. Management Science 42(4) 541-558.

Brynjolfsson, Erik, Yu Hu, Michael Smith. 2003. Consumer Surplus in the Digital Economy: Estimating the Value of Increased Product Variety. Management Science 49(11) 1580-1596.

Brynjolfsson, Erik, Yu Hu, Michael D. Smith. 2006. From Niches to Riches: Anatomy of the Long Tail. Sloan Management Review, 47 4(Summer) 67-71.

Brynjolfsson, Erik, Yu Hu, Mohammad Rahman. 2009. Battle of the Retail Channels: How Product Selection and Geography Drive Cross-channel Competition. Management Science 55(11) 1755-1765.

Brynjolfsson, Erik, Yu Hu, Michael D. Smith. 2010. Long Tails vs. Superstars: The Effect of Information Technology on Product Variety and Sales Concentration Patterns. Information Systems Research 4(21) 736-747.

Brynjolfsson, Erik, Yu Hu, Duncan Simester. 2011. Goodbye Pareto Principle, Hello Long Tail: the Effect of Search Costs on the Concentration of Product Sales. Management Science 57(8) 1373-1386.

BusinessWeek, 2005. http://images.businessweek.com/ss/05/12/bestideas/index_01.htm 
Chu, Junhong, Pradeep Chintagunta, and Javier Cebollada. 2008. A Comparison of Within-Household Price Sensitivity across Online and Offline Channels. Marketing Science 27(2), March-April 2008, pp. 283-299.

Elberse, Anita, Felix Oberholzer-Gee. 2007. Superstars and Underdogs: An Examination of the Long Tail Phenomenon in Video Sales. Marketing Science Institute 4 (2007): 49-72.

Elberse, Anita. 2008. Should You Invest in the Long Tail? Harvard Business Review 86(7/8) 88-96.

Fleder, Daniel, Kartik Hosanagar. 2009. Blockbuster culture's next rise and fall: The impact of recommender systems on sales diversity. Management Science 55(5) 697-712.

Forman, Chris, Anindya Ghose, Avi Goldfarb. 2009. Competition between Local and Electronic Markets: How the Benefit of Buying Online Depends on Where you Live. Management Science 55(1) 47-57.

Green, Chris. 2009. http://www.independent.co.uk/arts-entertainment/films/news/dvdrental-machines-to-be-launched-in-uk-supermarkets-1782926.html

Miller, Amalia, Catherine Tucker. 2011. Electronic Discovery and the Adoption of Information Technology. Working Paper. MIT Sloan School of Management, Cambridge, MA.

Oestreicher-Singer, Gal, Arun Sundararajan. 2011. Recommendation Networks and the Long Tail of Electronic Commerce. MIS Quarterly. Forthcoming.

Pozzi, Andreas. 2012. Shopping Cost and Brand Exploration in Online Grocery. American Economic Journal: Microeconomics, forthcoming.

Rosen, Sherwin. 1981. The Economics of Superstars. The American Economic Review, 71(5) 845-858.

Tucker, Catherine, Juanjuan Zhang. 2011. How does popularity information affect choices? A field experiment. Management Science 57(5) 828-842.

Waldfogel, Joel. 2012. And the Bands Played On: Digital Disintermediation and the Quality of New Recorded Music. Working Paper, University of Minnesota. Minneapolis, Minnesota. 


\section{Appendix: Sensitivity of Main Results to Redbox Kiosk Locations}

In this appendix we use historical data on the location of Redbox kiosks as of April 28, 2010 (the end of our study period is April 29 2010). We obtained these data from AggData LLC, a company that provides data to businesses and organizations. ${ }^{14}$ Tables A1 and A2 show that the conclusions in the main text are not affected when using only the information from individuals living in zip codes where Redbox was not present during our study period. Approximately one fourth of the focal company's consumers lived in zip codes without a Redbox's kiosk; these consumers made on average $26 \%$ of their transactions from physical stores (compared to $28 \%$ for all consumers) and rented a similar fraction of top 10, top 50, and top 100 DVD titles as other consumers do (comparing the mean of the dependent variables presented at the bottom of Tables 6 in the main text and A2). Table A1 shows that Redbox had substantially more presence in zip codes where our focal company also had a physical presence (the variable "Mean Number of Stores in the Zip Code Where the Household Resides" is 0.52 in Table 5 in the main text compared to 0.20 in Table A1).

${ }^{14}$ http://www.aggdata.com/ 
Table A1: Share of Offline Rentals - First Stage

\begin{tabular}{|l|c|}
\hline & I \\
\hline Number of Stores in the Zip Code Where the & $0.02727 * * *$ \\
\hline Household Resides (mean 0.20) & $(0.00244)$ \\
\hline Number of Stores in Zip Codes between Zero & $0.00494 * * *$ \\
\hline and Five Miles Away (mean 2.15) & $(0.00064)$ \\
\hline Number of Stores in Zip Codes between Five & $-0.00103 * * *$ \\
\hline and Ten Miles Away (mean 5.01) & $(0.00036)$ \\
\hline Number of Stores in Zip Codes between Ten & -0.00027 \\
\hline and Fifteen Miles Away (mean 6.33) & $(0.00034)$ \\
\hline Number of Stores in Zip Codes between Fifteen & $-0.00064 *$ \\
\hline and Twenty Miles Away (mean 6.57) & $(0.00034)$ \\
\hline Number of Stores in Zip Codes between Twenty & -0.00030 \\
\hline and Thirty Miles Away (mean 12.56) & $(0.00022)$ \\
\hline Total DVD Rentals & $0.02604 * * *$ \\
\hline (mean 2.23) & $(0.00016)$ \\
\hline Constant & $-0.02346 * *$ \\
\hline
\end{tabular}

Table A2: Share of Popular Rentals - IV Estimates - Second Stage

\begin{tabular}{|l|c|c|c|}
\hline & I & II & III \\
\hline Share of Offline Rentals & Top 10 & Top 50 & Top 100 \\
\hline (mean 0.26) & $0.4471 * * *$ & $0.3042 * * *$ & $0.3202 * * *$ \\
\hline Total DVD Rentals & $(0.0819)$ & $(0.1021)$ & $(0.1061)$ \\
\hline (mean 2.23) & $-0.0139 * * *$ & -0.0039 & -0.0026 \\
\hline Constant & $(0.0021)$ & $(0.0027)$ & $(0.0028)$ \\
\hline & $-0.0135 * * *$ & $-0.0239 * * *$ & $-0.0140 * * *$ \\
\hline Observations & $(0.0021)$ & $(0.0026)$ & $(0.0027)$ \\
\hline Includes fixed effects for both weeks (30) and individuals (378,160), and ZIP code-specific trends $(16,861)$. \\
\hline Standard errors in parentheses are clustered by household. & & \\
\hline The mean of the dependent variable is 0.20 in Column I, 0.39 in Column II, and 0.47 in Column III. \\
\hline$*$ significant at 10\%; ** significant at 5\%; *** significant at 1\% & & \\
\hline
\end{tabular}

